\title{
Panicoideae (Poaceae) de Ilha Grande, Piauí, Brasil
}

\author{
Panicoideae (Poaceae) from Ilha Grande, Piauí, Brazil
}

Maria Conceição Alves da Costa ${ }^{1}$, Maria Francilene Souza Silva ${ }^{1,2}$ \& Ivanilza Moreira de Andrade ${ }^{1}$

\begin{abstract}
Resumo
Este estudo compreende o levantamento taxonômico da subfamília Panicoideae (Poaceae) ocorrente no município de Ilha Grande, Piauí, Brasil. Foram registradas 17 espécies e 11 gêneros distribuídos na tribo Paniceae, 14 das espécies são novos registros para o Estado do Piauí. O gênero mais representativo foi Paspalum com cinco espécies. Axonopus compressus (Sw.) P. Beauv., é a única endêmica do Brasil e Paspalum vaginatum Sw. é utilizada para contenção de dunas. São apresentadas chaves para identificação das espécies, descrições, ilustrações, dados de distribuição e habitat.

Palavras-Chave: Gramineas, levantamento florístico, Rio Parnaíba, taxonomia.
\end{abstract}

\begin{abstract}
This study consists of a taxonomic treatment of the subfamily Panicoideae (Poaceae) in the municipality of Ilha Grande, Piauí State, Brazil, part of the Delta of the Rio Parnaíba. We recorded 17 species and 11 genera in tribe Paniceae, 14 of the species are new records for the state of Piauí. The largest genus is Paspalum with five species. Axonopus compressus (Sw.) P. Beauv. is the only species endemic to Brazil and Paspalum vaginatum Sw. is notable for its use in stabilizing sand dunes. An identification key, descriptions of all species, illustrations and notes on distribution and habitat of the species are provided.
\end{abstract}

Key words: Gramineae, floristic inventory, Rio Parnaíba, taxonomy.

\section{Introdução}

Poaceae inclui 793 gêneros e ca. 11.000 espécies (GPWG 2011). Estão registrados para o Brasil 216 gêneros e 1.445 espécies, e para o Piauí 59 gêneros e 145 espécies (Filgueiras et al. 2014), ocorrendo em ambientes como brejos, margens de cursos d'agua, matas, áreas de campo, cerrado e caatinga, e locais antropizados (Boldrini et al. 2008).

A família está dividida em 12 subfamílias (Viana \& Filgueiras 2008), sendo Panicoideae a maior em número de espécies com ca. de 220 gêneros e aproximadamente 3.300 espécies, distribuídas em 12 tribos (Boldrini et al. 2008). Panicoideae possui muitas espécies de expressiva importância econômica e ecológica, especialmente em Paspalum (Skerman \& Riveros 1992).

Panicoideae são ervas de ciclo estival, megatérmicas, caracterizada por lâminas foliares geralmente sésseis; espiguetas acrótona com articulação abaixo das glumas, raramente acima dela, e com dois antécios; espiguetas com um lema estéril e uma flor bissexuada; ou (1-)2 a muitas flores bissexuadas (Boldrini et al. 2008).

Estudos sobre a taxonomia, ecologia e fenologia desta subfamília para o Brasil foram realizados por diversos autores, como por exemplo Renvoize (1984), Longhi-Wagner (1987), Silva (2000), Oliveira \& Valls (2002, 2008), Viana \& Filgueiras (2008), Dias-Melo et al. (2009), Ferreira et al. (2009), Maciel et al. (2009, 2010, 2014), Longhi-Wagner (2012), Oliveira et al. (2013) e Pimenta et al. (2012). Há poucos tratamentos da diversidade natural de Poaceae no Piauí, os que enfocam especificamente as espécies do estado, ou de regiões dentro do estado, são Nascimento \& Renvoize (2001), Filgueiras et al. (2014) e Andrade et al. (2012), este ultimo sendo um precursor ao presente estudo.

\footnotetext{
${ }^{1}$ Universidade Federal do Piauí, Herbário Delta do Parnaíba-HDELTA, Campus Ministro Reis Velloso, Av. São Sebastião, 2819, 64202-020, Parnaíba, PI, Brasil.

${ }^{2}$ Autor para correspondência: lenolysilva@hotmail.com
} 
Diante do exposto, objetivou-se com este estudo realizar o levantamento de Panicoideae no município de Ilha Grande, Piauí, contribuindo para o conhecimento da diversidade, distribuição geográfica e conservação de espécies no Estado.

\section{Material e Métodos}

O município de Ilha Grande é um dos quatro municípios do litoral piauiense, inserido dentro da área de Proteção Ambiental do Delta do Rio Parnaíba, compreendendo uma área de 134,31 $\mathrm{km}^{2}\left(02^{\circ} 51^{\prime} \mathrm{S}, 41^{\circ} 49^{\prime} \mathrm{O}\right)$. Apresenta clima tropical megatérmico com chuvas de verão, temperatura média anual de $27,5^{\circ} \mathrm{C}$ e precipitação média anual de $800-1.600 \mathrm{~mm}$, tendo como trimestre mais úmido os meses de fevereiro a abril (Aguiar 2004).

O relevo da região compreende superfícies tabulares reelaboradas (chapadas baixas), superfícies suavemente onduladas, com altitude variando de 150 a 250 metros, e faixa litorânea (Jacomine et al. 1986). Os solos são principalmente arenosos, profundos, drenados e de baixa fertilidade. A vegetação identificada para área compreende caatinga, cerrado, restingas, mangue e floresta ciliar de carnaúba (Pfaltzgraff 2010).

Foram realizadas 10 expedições durante o período de agosto de 2010 a maio de 2014, em pontos selecionados do município de Ilha Grande, em áreas de restinga, Igarapés e margens de lagoas e rios. A coleta e herborização seguiram a metodologia padrão para plantas vasculares (Fidalgo \& Bononi 1984). A identificação dos táxons foi realizada por comparação com outros exemplares previamente identificados nos herbários locais (EAC, TEPB e HDELTA) ou com auxílio de literatura especializada. O material testemunho encontra-se depositado no Herbário Delta do Parnaíba (HDELTA) da Universidade Federal do Piauí.

A descrição dos táxons foi baseada nas amostras oriundas da área de estudo. As informações sobre o hábitat das espécies foram baseadas em observações de campo, e os dados de distribuição geográfica estão de acordo com a Lista de Espécies da Flora do Brasil (Filgueiras et al. 2014).

\section{Resultados e Discussão}

Foram registradas 17 espécies e 11 gêneros de Panicoideae distribuídas na tribo Paniceae, sendo Axonopus compressus (Sw.) P. Beauv. a única espécie endêmica do Brasil (Filgueiras et al. 2014). A maioria das espécies correspondem a novos registros para o estado.

\section{Chave para as espécies da subfamília Panicoideae}

1. Inflorescência em espiga ....

10. Paspalidium geminatum

1'. Inflorescência paniculada.

2. Espiguetas com cerdas involucrais na base.

3. Cerdas persistentes na raque após a queda das espiguetas maduras, livres entre si

17. Setaria parviflora

3'. Cerdas caducas com as espiguetas maduras, livres ou concrescidas, podendo formar um invólucro espinescente.

4. Cerdas tênues, às vezes plumosas, livres entre si.................16. Pennisetum purpureum

4'. Cerdas rígidas e espinescentes, concrescidas na base.....

2. Cenchrus echinatus

2'. Espiguetas sem cerdas involucrais na base.

5. Panícula nunca laxa, com ramos unilaterais espiciformes alternos a verticilados

6. Lígula ausente.

7. Panícula linear, espiguetas apiculadas

5. Echinochloa colona

7’. Panícula lanceolada, espiguetas aristadas

6. Echinochloa crusgalli

6'. Lígula presente.

8. Lema superior com o dorso rígido a cartáceo e margens hialinas, em geral envolvendo totalmente a pálea

3. Digitaria ciliaris

8'. Lema superior com igual consistência em toda a extensão, envolvendo parcialmente a pálea.

4. Digitaria sanguinalis

5'. Panícula laxa, às vezes com ramos unilaterais espiciformes alternos, conjugados ou verticilados. 
9. Espiguetas com glumas inferiores presentes.

10. Plantas cespitosas.

11. Panícula com ramos alternos, os basais mais longos que os apicais, com aspecto piramidal

12. Paspalum maritimum

11'. Panícula com ramos alternos a subverticilados de igual comprimento, sem aspecto piramidal.

12. Panícula com um a três ramos.

13. Panícula com um ramo simples

11. Paspalum flaccidum

13'. Panícula com 2-3 ramos unilaterais espiciforme conjugados ou subconjugados...

14. Paspalum vaginatum

12'. Panícula com 4 a mais ramos.

14. Panícula com 4-7 ramos unilaterais espiciformes alternos

15. Paspalum virgatum

14'. Panícula com 5-10 ramos verticilados

10. Paspalum fasciculatum

10'. Plantas decumbentes

13. Paspalum repens

9'. Espiguetas com glumas inferiores ausentes.

15. Ramos conjugados ou subdigitados, com espiguetas concrescidas .

1. Axonopus compressus

15'. Ramos nunca conjugados ou subdigitados, com espiguetas solitárias ou distantes entre si.

16. Plantas anuais, delicadas, decumbentes, estoloníferas.

8. Panicum trichoides

16'. Plantas perenes, robustas, cespitosa, em touceiras.

7. Megathyrsus maximum

1. Axonopus compressus (Sw.) P. Beauv., Ess. Agrostogr.: 12. 1812

Fig. 1a-c

Plantas estoloníferas, $30-50 \mathrm{~cm}$ alt., perenes. Bainha glabra, ciliada na margem; lígula 0,4-0,6 mm compr., membranosa-ciliada; lâmina $8-15 \times$ 1,3-2 cm, plana, lanceolada, glabra, raro pilosa, ápice obtuso, pelos curtos na margem. Panículas 10$23 \mathrm{~cm}$ compr., axilares, com 3 ramos subdigitados, às vezes conjugados. Espiguetas 1-1,5 × 0,8-1 $\mathrm{cm}$, concrescidas pediceladas, tricomas curtos nas nervuras. Gluma inferior ausente, gluma superior membranosa, lema inferior do mesmo tamanho da gluma, 1,5-2 $\times 0,7-1 \mathrm{~mm}$, mais longa que 0 antécio superior, aguda-apiculada, raramente glabra, 2-4 nervuras pouco evidentes, a nervura central ausente ou pouco conspícua. Antécio superior $1,9 \mathrm{~mm}$ compr., elipsoide a ovoide, glabro, estramíneo, subcoriáceo, papiloso, com tufo denso de tricomas no ápice. Fruto não visto.

Material examinado: Ilha do Urubu, 15.IV.2011, fl. e fr., M.C.A. Costa 330 (HDELTA); 29.IV.2011, fl., $L$. Araújo 87 (HDELTA).

É nativa e endêmica do Brasil, registrada para todo o país nos domínios Amazônia, Caatinga, Cerrado, Mata atlântica (Filgueiras et al. 2014). $\mathrm{Na}$ área de estudo habita próximo às margens de lagoas, em ambiente de dunas. Apresenta colmo oco e achatado, e nós levemente pilosos. É um registro novo para o estado.
2. Cenchrus echinatus L., Sp. P1.: 1050. 1753.

Fig. 1d-e, 4a

Plantas 40-60 cm alt., anuais, cespitosaeretas ou decumbentes. Bainha $6-7 \times 0,8-1,2 \mathrm{~cm}$, glabra na face abaxial, pelos na face adaxial nas margens e às vezes ao longo da nervura central; lígula $0,7-1 \mathrm{~cm}$ compr., pilosa; lâmina $10-32 \times$ 1,2-2,5 cm, lanceolada, ápice agudo, margem pilosa, base larga, glabra na face adaxial e às vezes escabra na abaxial. Panículas contraídas, 10-18 $\times$ $1,3-2,8 \mathrm{~cm}$, raque ereta ou flexível; setas flexíveis, retrorso-escabras na base não ultrapassando a espigueta, cerdas involucrais na base, caducas com as espiguetas maduras, concrescidas até acima da metade do invólucro formando um invólucro rígido e espinescente, escabras, achatadas, disposta em uma única série. Espiguetas 1-4 por invólucro, pediceladas; plurifloras; flores casmógamas, bissexuadas ou unissexuadas, gluma inferior 1-1,5 mm compr., 1 nervura, central, gluma superior com 5 nervuras; lema fértil, gluma e lema glabras. Estames ca. $2 \mathrm{~mm}$ compr. Fruto não visto.

Material examinado: Morro da Mariana, 05.X. 2011, fl., M.C.A. Costa 367 (HDELTA).

Conhecida popularmente como carrapicho, sendo nativa e registrada em todo Brasil. Ocorre nos domínios Amazônia, Caatinga, Cerrado, Mata Atlântica e Pantanal (Filgueiras et al. 2014). É 
comum em toda a área de estudo e um registro novo para o estado.

\section{Digitaria ciliaris (Retz.) Koeler, Descr. gram.:} 27. 1802.

Fig. 1f-g

Plantas $15-50 \mathrm{~cm}$ alt., anuais, estoloníferas, eretas às vezes decumbentes. Bainha $0,1-0,2 \mathrm{~mm}$ compr., hirsuta, com tricomas tuberculados; lígula $0,7 \times 1,2 \mathrm{~cm}$ compr., ciliada; lâminas 3-18 $\times 0,3-$ $0,5 \mathrm{~cm}$, linear-lanceolada, glabra ou com densos tricomas na face adaxial, ápice agudo. Panículas 5,4-8,9 cm compr., com ramos unilaterais espiciformes, 4-9 ramos subverticilados no ápice da inflorescência, 1-2 ramos inferiores ao ápice, subdigitados, ráqui alada, glabra. Espiguetas 0,4$0,5 \mathrm{~mm}$, pediceladas, lanceoladas, homomorfas, pubescentes, tricomas longos esbranquiçados presentes na gluma superior e lema inferior; gluma inferior $0,2-0,3 \mathrm{~mm}$ compr., ápice agudo, e superior $1,2-1,8 \mathrm{~mm}$ compr., aguda, $1 / 2$ a $3 / 4$ do compr. do lema inferior, 3 nervuras, lema inferior com margem ciliada, 7 nervuras laterais glabras ou raramente escabras no ápice, glabro em ambos os lados da nervura central, lema superior com o dorso rígido a cartáceo e margens hialinas, em geral envolvendo totalmente a pálea. Fruto não visto.

Material examinado: Morro da Mariana, 05.IV. 2011, fl., M.C.A. Costa 363 (HDELTA).

É subespontânea no Brasil e registrada em todo o país, ocorrendo nos domínios Amazônia, Caatinga, Cerrado, Mata Atlântica, Pampa, Pantanal (Filgueiras et al. 2014). É comum na área de estudo sobre solos arenosos da Restinga e trata-se de registro novo para o estado.

4. Digitaria sanguinalis (L.) Scop., Fl. Carniol. (ed. 2) 1: 52. 1771.

Fig. 1h

Plantas $0,4-1 \mathrm{~m}$ alt., anuais, cespitosas, decumbentes. Bainha 3-8 cm compr., glabra, raramente pilosa na base da região externa; lígula $0,5-0,8 \mathrm{~cm}$ compr., ciliada. Lâminas $5-17$ $\times 3-12 \mathrm{~mm}$, planas, lanceoladas, glabras, ápice agudo, borda escabra, base com tricomas longos. Panícula 5-9 cm compr., 2-7 ramos unilaterais espiciformes verticilados. Espiguetas 4,2-5,3 mm, pediceladas, solitárias, ráquis alados levemente pilosos, 2-3 antécio surgindo de um só ponto da ráqui; gluma superior $2-3 \mathrm{~mm}$ compr., menor que a gluma inferior com tricomas próximo das nervuras laterais, 4-6 nervuras, sem arista, gluma inferior 2,5-3,5 mm, obtusa, maior que o lema, 4-6 nervuras, glumas persistentes, lema $1,2-2$ mm compr., 2-3 nervuras, sem arista, glabro, lema superior com igual consistência em toda a extensão, envolvendo parcialmente a pálea; pálea tão longa quanto o lema. Fruto não visto.

Material examinado: Tatus, 17.XI.2010, fl., M.C.A. Costa 276. (HDELTA); ib., 17.XI.2010, fl., M.C.A. Costa 366 (HDELTA).

É subespontânea e registrada para o Sul no domínio Pampa (Filgueiras et al. 2014). É comum em toda a área de estudo, sobre solos arenosos, ocorrendo em simpatria com $D$. ciliaris em área de restinga. É um registro novo para o estado.

5. Echinochloa colona (L.) Link, Hort. Berol. 2:209. 1833

Fig. 1i-k

Plantas 26-50 cm alt., anuais, estoloníferas, sem rizoma. Bainha 5-9 × 0,4-0,8 cm, glabra ou com pelos curtos na face abaxial; lígula ausente; lâmina 8-17 × 4-10 cm, linear, lanceolada, ápice agudo, larga na base, margem inteira, glabras em ambas as faces, às vezes pilosa. Panícula 10-15 $\mathrm{cm}$ compr., linear, ramos unilaterais espiciformes, alternos, 6-12 ramos simples. Espiguetas 3,2-4 $\times 0,8-1,3 \mathrm{~cm}$, solitárias, obovais ou elípticas, apiculadas, escabras ou híspidas; gluma inferior 1,2-1,5 mm compr., 3-5 nervuras, híspidas, tricomas do mesmo tamanho em todas as nervuras $\mathrm{e}$ entre as nervuras, aristado, gluma superior 2,2-3,1 $\times 0,8-1 \mathrm{~cm}, 4-6$ nervuras, híspida, apicular, lisa ou escabra entre as nervuras, aristado, lema inferior 2,2-3,3 mm compr., 5-6 nervuras, híspido, escabro entre as nervuras, levemente piloso, carístula apiculada; pálea inferior 1,5-2,1 × 0,7-1 mm. Fruto não visto.

Material examinado: Morro Branco, 05.X. 2011, fl., M.C.A. Costa 339 (HDELTA).

Conhecida popularmente como coloninho, subespontânea e registrada em todo Brasil, ocorrendo nos domínios Amazônia, Caatinga, Cerrado, Mata Atlântica (Filgueiras et al. 2014; Lorenzi 2006). Na área de estudo ocorre geralmente como planta ruderal, em áreas degradadas e margens de estradas.

6. Echinochloa crus-galli (L.) P. Beauv., Ess. Agrostogr.: 53. $1812 . \quad$ Fig. 11-n

Plantas $0,6-1,5 \mathrm{~m}$ alt., anuais, cespitosas, eretas e decumbentes. Bainha $5-14 \times 0,2-0,5 \mathrm{~cm}$, glabra, margem inteira; lígula ausente; lâmina $7-20 \times 0,2-0,6 \mathrm{~cm}$, plana, lanceolada, glabra, raramente pilosas na face adaxial, margem com tricomas curtos, escabros, ápice agudo. 


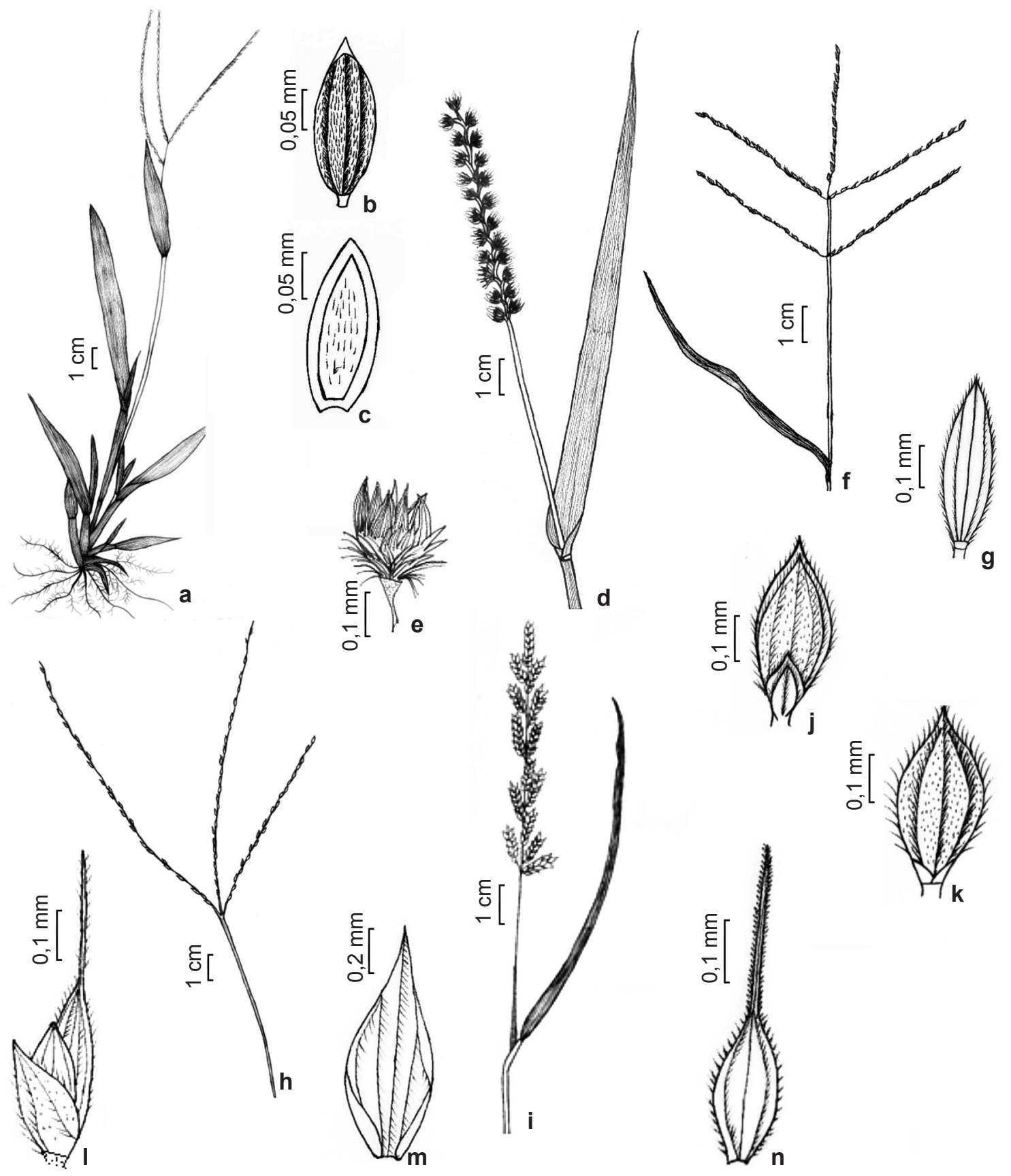

Figura 1 - a-c. Axonopus compressus (Sw.) P. Beauv. - a. hábito com inflorescência; b. espigueta vista ventral;c. espigueta vista dorsal; d-e. Cenchrus echinatus L.- d. inflorescência; e. espigueta; f-g. Digitaria ciliaris (Retz.) Koeler - f. inflorescência; g. espigueta; h. Digitaria sanguinales (L.) Scop. - h. inflorescência; i-k. Echinochloa colona (L.) Link - i. inflorescência ; j. espigueta com vista ventral ; k. vista dorsal; 1-n. E. crusgalli (L.) P. Beauv. - 1. espigueta; $\mathrm{m}$. gluma inferior ; n. lema.

Figure 1 - a-c. Axonopus compressus (Sw.) P. Beauv. - a. habit with inflorescence; b. spikelet ventral view; c. spikelet dorsal view; d-e. Cenchrus echinatus L. - d. inflorescence; e. spikelet; f-g. Digitaria ciliaris (Retz.) Koeler - f. inflorescence; g. spikelet; h. Digitaria sanguinales (L.) Scop. - h. inflorescence; i-k. Echinochloa colona (L.) Link - i. inflorescence ; j. spikelet, ventral view ; k. spikelet, dorsal view; 1-n. E. crusgalli (L.) P. Beauv. - 1. spikelet; m. lower glume; n. lemma. 
Panícula espiciforme, lanceolada, 15-20 ramos unilaterais, alternos a verticilados. Espiguetas $0,8-1,2 \mathrm{~cm}$ compr., pediceladas, aristadas, escabras ou híspidas; gluma inferior $0,8-1,2 \times 0,08-0,1 \mathrm{~cm}$, 3-7 nervuras pilosas, escabras ou híspidas entre as nervuras, gluma superior 3-4 × 1-1,8 mm, escabra, aristada, 3-5 nervuras híspidas, ausência de pelos na nervura central, lema inferior $0,8-1,4 \times 08-0,2$ $\mathrm{cm}$, arista $0,8-1,2 \mathrm{~mm}$ compr., escabra, densamente piloso, 3-7 nervuras; pálea $1-1,5 \times 0,5-1 \mathrm{~mm}$, mútica, não hispida. Fruto não visto.

Material Examinado: Parelhas, 04.IX. 2011, fl., M.C.A. Costa 345 (HDELTA).

Segundo Filgueiras et al. (2014) é subespontânea e ocorre em todo o Brasil. Na área de estudo cresce na margem de lagoas. Trata-se de registro novo para o estado.

7. Megathyrsus maximum (Jacq.) B. K. Simon \& S.W.L. Jacobs., Icon. Pl. rar. 1:2. 1781

Fig. 2a-d, $4 \mathrm{~b}$

Plantas 1-2 m alt., perenes, robustas, rizomatosas, cespitosas. Bainha glabra ou pilosa, não quilhada, margens ciliadas; lígula externa ausente; lâmina $10-65 \times 1-2,2 \mathrm{~cm}$, linear-lanceolada, ápice agudo, glabra ou com tricomas longos na face adaxial e curto na face abaxial, margens com tricomas rígidos ou escabros. Panícula laxa, ramos verticilados na base e alternos no ápice; raque com pelos curtos esbranquiçados, não alados; espiguetas 3-4 cm compr., solitárias, com pedicelo de tamanhos diferentes, estreitamente elípticas, glabras; glumas persistentes, múticas; gluma inferior 1-1,7 mm compr., menor que a espigueta, base abraçando a gluma superior com 1-3 nervuras, ápice obtuso, lema 2,3-3,1 mm compr., não aristado, com 3-5 nervuras, rugoso, pálea 2-3 mm compr. envolvendo toda flor. Fruto não visto.

Material Examinado: Morro Branco, 18.I. 2011, fl., M.C.A. Costa 292 (HDELTA).

Registrada para o Brasil ocorrendo nos domínios Amazônia, Caatinga, Cerrado, Mata Atlântica, Pantanal. É conhecida como capimcolonião ou capim-elefante, habita áreas alagáveis nas margens de lagoas e cursos d'água, trata-se de registro novo para o estado.

\section{Panicum trichoides Sw., Prodr.: 24. 1788.}

Fig. 2e-g, 4c

Plantas anuais, estoloníferas, decumbentes, 20-30 cm alt. Colmo oco, cilíndrico, com entrenós e nós glabro e flexível, ereto ou às vezes, decumbente. Bainhas $1-5 \mathrm{~cm}$ compr., pilosa na face adaxial, glabra na abaxial; lígula ciliada; lâmina 2,8-6,5 cm compr., lanceolada, ápice agudo, base larga, pilosa. Panículas 5-15 cm compr., laxas, esverdeada, nas axilas terminais, ramos com espiguetas distantes entre si. Espiguetas uni a plurifloras, glabras, não híspida, sem arista, gluma inferior obovada menor que a superior, 1-3 nervura, margem arroxeada, gluma superior 3-5 nervuras, permanentes; antécio inferior estéril; lema 3-5 nervuras, lema superior finamente granuloso. Fruto não visto.

Material examinado: Porto das Barcas, 05.III. 2011, f1., M.C.A. Costa 342 (HDELTA); 29.IV. 2011, fl., $L$. Araujo 342 (HDELTA).

É nativa e registrada no Norte, Nordeste, Centro-Oeste e Sudeste, nos domínios Amazônia, Caatinga, Cerrado, Pantanal (Filgueiras et al. 2014). Ocorre geralmente como planta ruderal, em áreas degradadas e margens de estradas. Trata-se de registro novo para o estado.

9. Paspalidium geminatum (Forssk.) Stapf., Fl. Trop. Afr. 9: 583. $1920 \quad$ Fig. 3f-h, 4d

Plantas $0,4-1 \mathrm{~m}$ de altura, anuais ou perenes, cespitosas, eretas ou decumbentes. Bainha 2,5-15 $\times 0,3-0,8 \mathrm{~cm}$, glabra; lígula $0,3-0,8 \mathrm{~cm}$ compr., ciliada; lâmina 3-11 × 1,4-2,8 cm, lanceolada, glabra na face dorsal e pilosas na face adaxial. Espiga dística, flexível, ramos simples não axilares; raque alada, glabra com tricomas nas margens; gluma superior 2,2-3 × 1-1,3 mm, obovada, 5-8 nervuras glabras, múltiplas, gluma inferior $0,5-1$ $\times 0,6-1 \mathrm{~mm}$, glabra, múltipla, não híspida com 1-3 nervuras pouco visíveis; lema inferior 1,8-2,2 $\times 1-1,3 \mathrm{~mm}$, múcron com 5-7 nervuras glabras. Fruto não visto.

Material examinado: Morro da Mariana, 15.II.2011, fl. e fr., M.C.A. Costa 367 (HDELTA).

É nativa e registrada para o Nordeste (MA, CE), Sudeste (RJ), ocorre nos domínios Amazônica, Caatinga, Mata Atlântica (Filgueiras et al. 2014). São plantas consideradas macrófitas do tipo anfíbia, ocorrem em ambientes de brejos, nas margens de rios e lagoas, próximas às dunas. Trata-se de registro novo para o estado.

10. Paspalum fasciculatum Willd. Ex Flüggé, Gram. Monogr., Paspalum: 69. 1810. Fig. 2i-j

Plantas 0,8-1,6 $\mathrm{m}$ alt., perenes, cespitosas, estoloníferas, decumbentes. Bainha 5-15 × 0,8-1,2 $\mathrm{cm}$, glabra na face abaxial, pelos longos na base adaxial; lígula $0,5-0,9 \mathrm{~cm}$ compr., membranácea; lâmina 6-13 × 0,8-1,2 cm, linear, lanceolada, ápice agudo, base larga, glabra ou subpilosa na base, 
margens revolutas, com pelos curtos. Panículas, ramos unilaterais espiciformes, verticilados no ápice, geralmente glabros, 9-14 ramos, 2-17 cm compr., os ramos inferiores menores 2-2,7 mm compr., os superiores 10-17 cm compr.; ráqui glabro, não alado. Espiguetas solitárias, 3,8-4,2 × 0,9-1,2 mm; inferiores sésseis e superiores pediceladas, elípticas, lanceolada, acuminada com pelos nas margens; gluma inferior ausente, gluma superior 2,8-3,1 mm compr., 5-7 nervuras, com pelos esbranquiçados, mútica, híspida; lema inferior 2,2-2,7 × 0,6-0,8 mm, com 3-6 nervuras, não híspidas; pálea ausente; antécio superior 2,7-3,2 × 0,6-0,9 mm, glabro. Cariopse 2,3-3 compr., branca.

Material examinado: Morro da Mariana, 18.I.2011, fl. e fr., M.C.A. Costa 295 (HDELTA).

É nativa e registrada para o Norte, CentroOeste, Sudeste nos domínios Amazônia, Cerrado, Pantanal (Filgueiras et al. 2014). Na área de estudo ocorre geralmente como planta ruderal, em áreas degradadas e margens de estradas. É um registro novo para o estado.

11. Paspalum flaccidum Nees, F1. Bras. Enum. P1. 2(1): 48-49. 1829.

Fig. 2h

Plantas 15-40 cm alt., perenes, cespitosas, eretas ou decumbentes. Bainha 1-7 ×0,1-0,3 cm, glabra, raramente pilosa; lígula $0,6-0,8 \mathrm{~mm}$ compr., pilosa; lâmina $1-10 \mathrm{~cm} \times 1-5 \mathrm{~mm}$, lanceoladas, ápice agudo, face abaxial glabra, face adaxial levemente pilosa. Panícula simples e terminal, 4-8 cm compr., raque glabra ou com tricomas muito curtos. Espiguetas pediceladas, glabras, unissexuadas ou bissexuadas, espiguetas binadas, estramíneas ou vináceas, obovais, agudas; gluma superior 2-3,3 $\times$ 0,8-1,1 mm, glabra, aristada, 3-5 nervuras, gluma inferior ausente, gluma superior com 3 nervuras, glabra, membranosa, não alada, lema com 5 nervuras, glabro, membranoso, não plicado; antécio inferior neutro; pálea ausente. Fruto não visto.

Material examinado: Pantanal, 10.IV. 2010, fl., R.B. Reis 366 (HDELTA).

É nativa, registrada para o Centro-Oeste, Sudeste e Sul e ocorre nos domínios Cerrado e Mata Atlântica (Filgueiras et al. 2014). Na área de estudo ocorre geralmente nas margens de lagoas, e trata-se de registro novo para o estado.

12. Paspalum maritimum Trin., Mém. Acad. Imp. Sci. Saint-Pétersbourg, Sér. 6, Sci. Math., Seconde Pt. Sci. Nat. 3,1(2-3): 148. 1834. Fig. 21-m, 4e

Plantas 60-98 cm alt., perenes, cespitosas, eretas. Bainha $7-15 \times 0,6-0,8 \mathrm{~cm}$, glabra ou com tricomas longos tuberculados, margem glabra; lígula 1-2 mm compr. ciliada; lâmina 10-17 × 0,6-1,2 cm, lanceolada, plana, ápice agudo, larga na base, glabra na face abaxial, com pelos muito curtos ou longos 3-5 mm compr., localizados próximo à margem. Panícula, ramos unilaterais espiciformes, alternos, 8-18 desiguais, os da base 9-11 cm compr., os do ápice 4-9 cm compr., piramidal; raque levemente pilosa. Espiguetas 1,8-2 mm compr., pediceladas; gluma inferior com 1-3 nervuras, híspida, envolvida totalmente por pelos longos esbranquiçados, mútica, obovada, gluma superior 1-2 nervuras, com pelos no centro; lema glabra 1,7-2 mm rígida, 1-3 nervuras; pálea 1,5-1,8 mm compr., glabra com 1 nervura central ou às vezes ausente. Fruto não visto.

Material examinado: Morro Branco, 26.I.2010, fl., M.C.A. Costa 306 (HDELTA).

Conhecida popularmente como capimgengibre, é nativa, registrada para o Norte, Nordeste, Centro-Oeste, Sudeste, ocorrendo nos domínios Amazônia, Caatinga, Cerrado, Mata Atlântica (Filgueira et al. 2014). É utilizada como forrageira pela a população local, na alimentação do gado. Na área de estudo ocorre geralmente como planta ruderal, em áreas degradadas e margens de estradas. É um registro novo para o estado.

13. Paspalum repens P.J.Bergius, Acta Helv. Phys.Math. 7:129. 1772.

Fig. 2n-p, $4 \mathrm{f}$

Plantas aquáticas, 1-2 $\mathrm{m}$ alt., perenes, decumbentes. Bainha 6,4-11,2 × 1,7-3,4, levemente pilosa próxima à margem; lígula 1,4-1,9 mm compr.; lâmina 23-35,2 × 1-1,9, lanceolada, plana, aguda, tuberculado-pilosa em ambas as faces. Panícula terminal, 24-30 ramos, 1,2-3,8 cm, alternos ou em fascículos; raque alada, margens foliáceas, encobrindo parcialmente as espiguetas, esverdeadas, escabras nas margens. Espiguetas 2-2,2 × 1,6-1,9 mm, solitárias, estamíneas, elípticas, acuminadas; gluma inferior ausente; gluma superior e lema inferior mais longos que o antécio superior, 2-3 nervuras, pubescentes a glabros, membranosos, gluma não a lada; lema não plicado, sem nervuras aparentes, glabros; pálea ausente. Fruto não visto.

Material examinado: Parelhas, 26.V. 2010, fl., M.C.A. Costa 345 (HDELTA).

É nativa, registrada para todo país ocorrendo nos domínios Amazônia, Caatinga, Cerrado, Mata Atlântica, Pampa e Pantanal (Filgueiras et al. 2014). São aquáticas emergentes encontradas na área de estudo em rios e lagoas com pouca 


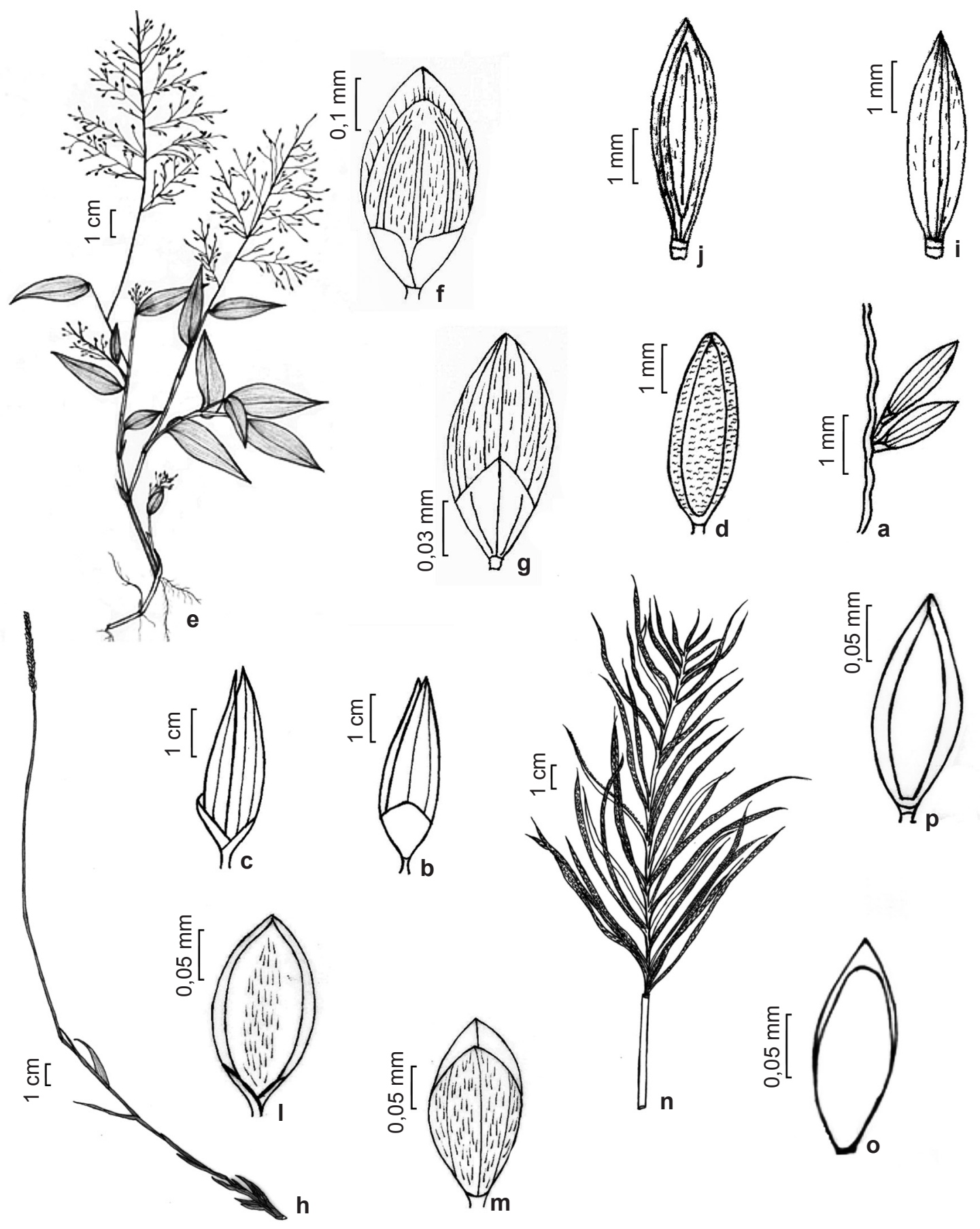

Figura 2 -a-d. Megathyrsus maximum (Jacq.) B. K. Simon \& S. W. Jacobs - a. espigueta acrótona; b. espigueta vista ventral; c. espigueta vista dorsal; d. lema; e-g. Panicum trichoides Sw. - e. hábito e inflorescência; f. espigueta vista dorsal; g. espigueta vista ventral; h. Paspalum flaccidum Nees - h. Hábito e inflorescência; i-j. P. fasciculatum Willd. ex Flugge-i. espigueta com vista ventral; j. espigueta com vista dorsal; 1-m. P. maritimum Trin. - i. espigueta com vista dorsal; m. espigueta ventral; $n$-p. $P$. repens $\mathrm{P} . J$. Bergius $-\mathrm{n}$. inflorescência; o. antécio com vista ventral; $\mathrm{p}$. antécio com vista dorsal.

Figure 2 - a-d. Megathyrsus maximum (Jacq.) B. K. Simon \& S. W. Jacobs - a. spikelet acrotona; b. spikelet ventral view; c. spikelet dorsal view; d. lemma; e-g. Panicum trichoides Sw. - e. habit and inflorescence; f. spikelet, dorsal view; g. spikelet, ventral view; h. Paspalum flaccidum Nees -h. habit and inflorescence; i-j. P. fasciculatum Willd. ex Flugge - i. spikelet, ventral view; j. e spikelet, dorsal view; 1-m. P. maritimum Trin. - 1 . spikelet, dorsal view; $m$. spikelet ventral view; n-p. P. repens P.J. Bergius - n. inflorescence; o. anthecium, ventral view; p. anthecium, dorsal view. 
correnteza e utilizadas como planta forrageira, na alimentação do gado pela população local.

14. Paspalum vaginatum Sw., Prodr.: 21. 1788.

Fig. 3a-c

Plantas 10-30 cm alt., perenes, cespitosas, estoloníferas, rizoma curto. Bainha $2-10 \times$ 1,8-3,0 cm, glabra; lígula $0,4-1,3 \mathrm{~mm}$ compr.; lâmina linear, glabra, plana, rígida, glauca, convoluta ou subconvoluta, aguda e estreita na base. Panícula terminal, 2-3 ramos, conjugados ou subconjugados; raque não aladas, glabras; pedicelado, glabro. Espiguetas 3,3-6,2 × 2-3 $\mathrm{mm}$, solitárias, estamíneas, elíptico-lanceoladas a elíptico-ovais, fortemente agudas, gluma inferior ausente, gluma superior mais longa que o antécio superior, 2-4 nervuras, glabras, membranosas, não aladas; lema inferior mais longo que o antécio superior, 3-5 nervuras, glabro, membranoso, não plicado. Fruto não visto.

Material examinado: Morro da Mariana, 13.IX. 2010, fl., L. R. Andrade 02 (HDELTA).

É nativa e ocorre em todo o país nos domínios Amazônia, Cerrado, Mata Atlântica, Pantanal (Figueiras et al. 2014). Na área de estudo ocorre geralmente em dunas, sendo utilizada inclusive para a contenção das mesmas. É um registro novo para o estado.

15. Paspalum virgatum L., Syst. Nat. (10 ed.) 2: 855. 1759.

Fig. 3d-e

Plantas 20-70 cm compr., perenes, cespitosas, estoloníferas. Bainha 20-40 $\times$ $0,4-0,7 \mathrm{~cm}$, glabra; lígula $0,5-1,2 \mathrm{~mm}$ compr., ciliada; lâmina 15-40 × 0,4-0,9 cm, plana, lanceolada, ápice agudo, glabra, margem escabra com tricomas rígidos e curtos. Panícula, ramos unilaterais espiciformes, alternos, 4-7 ramos. Espiguetas pediceladas, solitárias, raque glabra ou levemente pilosa, alada, tricomas longos 3-5 mm compr. na base dos ramos; gluma inferior 2-2,5× 0,8-1 mm, mútica, híspida, com 1 nervura central, a gluma superior 2-2,2 mm compr., glabra com 2 nervuras laterais, nervura central ausente; lema $1,2-1,7 \times 0,8-1 \mathrm{~mm}$, glabro, rugoso, ápice agudo, glabro, mútico, com 1 nervura central ou ausente. Cariopse branca.

Material examinado: Morro da Mariana, 18.I.2011, fl., M.C.A. Costa 366 (HDELTA); 05.V.2011, fl., M. C. A. Costa 392 (HDELTA).

É nativa e ocorre em todo o país nos domínios Amazônica, Cerrado, Mata Atlântica, Pantanal (Filgueiras et al. 2014). Na área de estudo ocorre geralmente como planta ruderal, em áreas degradadas e margens de estradas e um registro novo para o estado.

16. Pennisetum purpureum Schumach. Beskr. Guin. Pl.: 44. 1827.

Fig. $3 \mathrm{i}$

Plantas $1-1,8 \mathrm{~m}$ alt., perenes, estoloníferas, cespitosas, eretas. Bainha $80-15 \times 0,4-1 \mathrm{~cm}$; lígula 1,8-2,7 mm compr., pilosa; lâmina 15-35 × 4-7 $\mathrm{cm}$, plana, lanceolada, ápice agudo, glabra a pilosa em ambas as faces, margem ciliada à escabra. Panículas $12-33 \mathrm{~cm}$ compr., ramos espiciformes terminais, eretos, flexíveis, cilíndricos, arroxeados ou amarelados, raque glabra ou raramente pilosa, não alada. Espiguetas $2-1,5 \times 0,1-0,3 \mathrm{~cm}$, solitárias, cerdas involucrais na base envolvendo 1-3 espiguetas, tênues, às vezes plumosas, caducas com as espiguetas maduras, livres; 1-3 antécio contém uma cerda maior e mais espessa que as demais; gluma inferior $1,2-1,8 \times 0,7-0,1 \mathrm{~mm}$ ou ausente, a superior 1,1-1,5 mm compr., antécio inferior neutro ou com flor masculina, lema 3-4,5 mm compr., 3-5 nervuras, pálea 2,2-3 mm compr., raramente ausente, pálea menor que o lema. Fruto não visto.

Material examinado: Tatus, 05.V.2011, fl., M.C.A. Costa 339. (HDELTA).

É subespontânea e registrada para o Norte, Nordeste, Centro-Oeste, Sudeste nos domínios Amazônia, Caatinga, Cerrado, Mata Atlântica (Filgueiras et al. 2014. Na área de estudo ocorre geralmente como planta ruderal, em áreas degradadas e margens de estradas. É um registro novo para o estado.

17. Setaria parviflora (Poir.) Kerguélen, Lejeunia 120: 161. 1987.

Fig. 3j-k

Plantas 60-90 cm alt., anuais ou perenes, cespitosas, rizomatosas. Bainha cilíndrica, glabra, raramente pilosa; lígula $2-3 \mathrm{~mm}$ compr., ciliada com tricomas curtos e longos; lâmina 10-20 cm compr., plana, linear-lanceolada, face adaxial escabra, abaxial glabra. Panícula 8-20 cm compr., ramos espiciformes contraídos, eretos. Espiguetas pediceladas, ovais, 2-7 mm compr., 2-12 cerdas involucrais na base, persistentes na raque após a queda das espiguetas maduras, livres entre si; gluma inferior com 3-5 nervuras, glabra, mútica, a superior com 4-6 nervuras, glabra; lema inferior 4-7 nervuras, rugosas. Fruto não visto.

Material examinado: Tatus, 17.XI.2010, fr., M.C.A. Costa 278 (HDELTA). 

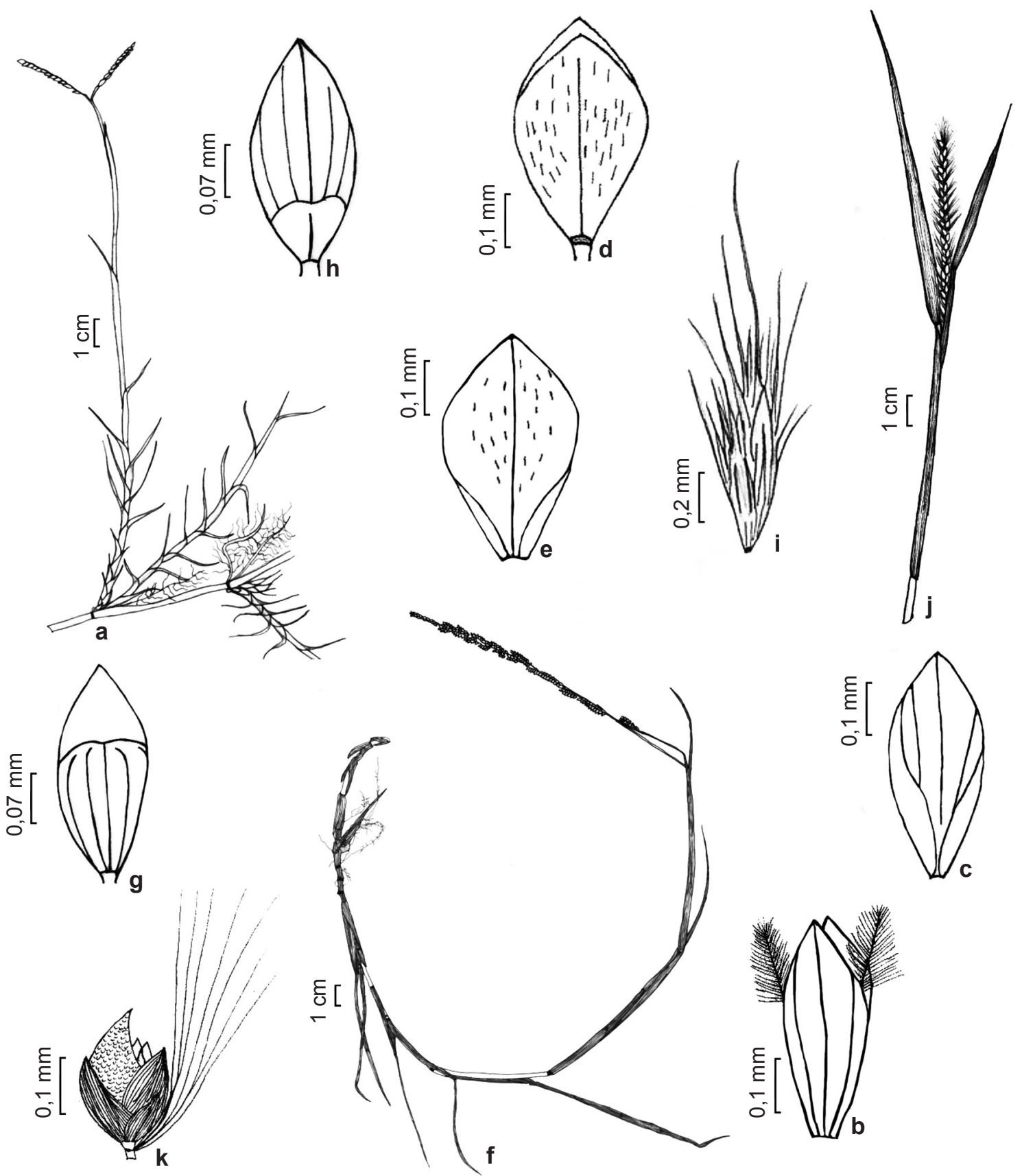

Figura 3 - a-c. Paspalum vaginatum Sw. - a. hábito e inflorescência; b. gluma superior; c. gluma inferior; d-e. $P$. virgatum L. - d. espigueta vista ventral;, e. gluma inferior; f-h. Paspalidium geminatum (Forssk) Stapf $-\mathrm{f}$. hábito e inflorescência; g. espigueta face dorsal; h. espigueta vista ventral; i. Pennisetum purpureum Pei - i. inflorescência j-k. Setaria parviflora (Poir.) Kerguélen - i. espigueta com cerdas; j. inflorescência. k. gluma.

Figure 3 - a-c. Paspalum vaginatum Sw. - a. habit and inflorescence; b. upper glume ; c. lower glume; d-e. P. virgatum L. - d. spikelet, ventral view; e. lower glume; f-h. Paspalidium geminatum (Forssk.) Stapf $-\mathrm{f}$. habit and inflorescence; g. spikelet, dorsal face; h. spikelet, ventral view; i. Pennisetum purpureum Pei - i. inflorescence; j-k. Setaria parviflora (Poir.) Kerguélen - i. spikelet with bristles; j. inflorescence. k. glume 

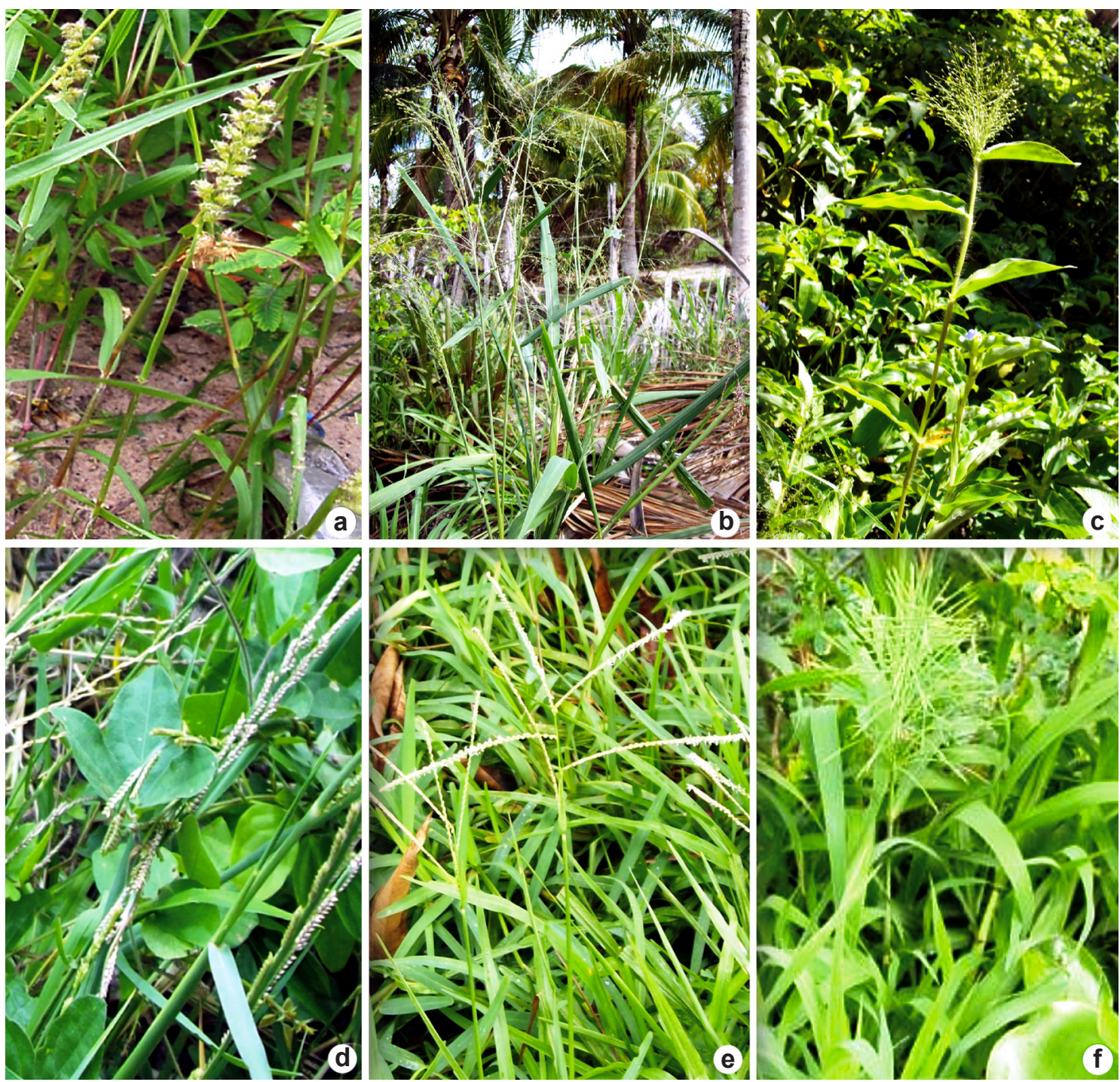

Figura 4-Espécies da subfamília Panicoideae do Município de Illha Grande, Piauí, Brasil. a. Cenchrus echinatus L.; b. Megathyrsus maximum (Jacq.) B. K. Simon \& S. W. Jacobs; c.Panicum trichoides Sw.; d. Paspalidium geminatum (Forssk) Stapf; e. P. maritimum Trin.; f. P. repens P.J. Bergius.

Figure 4-Species of subfamily Panicoideae in the municipality of Ilha Grande, Piaú, Brazil. a. Cenchrusechinatus L.; b. Megathyrsus maximum (Jacq.) B. K. Simon \& S. W. Jacobs; c. Panicum trichoides Sw.; d. Paspalidium geminatum (Forssk) Stapf; e. P. maritimum Trin.; f. P. repens P.J. Bergius.

É subespontânea e registrada para o Norte, Nordeste, Centro-Oeste e Sudeste (Filgueiras et al. 2014). Na área de estudo foi encontrada em dunas.

\section{Agradecimentos}

Ao CNPq o suporte financeiro para o projeto Biodiversidade de Macrófitas Aquáticas do Delta do Parnaíba (processo no. 503494-2009-7), ao Sistema de Autorização e Informação em Biodiversidade, a equipe do projeto o auxílio nos trabalhos de campo e aos curadores dos Herbários visitados.

\section{Referências}

Aguiar, R. 2004. Projeto cadastro de fontes de abastecimento por água subterrânea, Estado do Piauí: Diagnóstico do município de Parnaíba. In: Aguiar, R. \& Gomes, J. Projeto cadastro de fontes de abastecimento por água subterrânea Piauí. Serviço Geológico do Brasil, Brasília. 17p.

Andrade, I.; Silva. M.; Mayo, S.; Silva, A.; Silva, A.; Braz, G.; Nascimento, H.; Melo, L.; Costa, M.; Nascimento, M.; Reis, R. \& Santos, R. 2012. Diversidade de Fanerógamas do Delta do Parnaíba - Litoral Piauiense. In: Guzzi, A. Biodiversidade 
do Delta do Parnaíba: litoral piauiense. Editora da Universidade Federal do Piauí, Parnaíba. Pp. 63-115.

Boldrini, I.; Longhi-Wagner, H. \& Boechat, S. 2008. Morfologia e Taxonomia de Gramíneas Sul-RioGrandenses. Editora UFRGS, Porto Alegre. 87p.

Dias-Melo, R.; Ferreira, M. F. \& Forzza, R.C. 2009. Panicoideae (Poaceae) no Parque Estadual de Ibítipoca, Minas Gerais-Brasil. Boletim de Botânica da Universidade de São Paulo 27: 153187.

Ferreira, C.; Oliveira, R.; Valls, J. \& Loiola, M. 2009. Poaceae da estação ecológica do Seridó, Rio Grande do Norte, Brasil. Hoehnea 36: 679-709.

Fidalgo, O. \& Bononi, V. 1984. Técnicas de coleta, preservação de material botânico. Instituto de Botânica, São Paulo. 62p.

Filgueiras, T.; Longhi-Wagner, H.; Viana, P.; Zanin, A.; Oliveira, R.; Canto-Dorow, T.; Shirasuna, R.; Valls, J.; Oliveira, R.; Rodrigues, R.; SantosGonçalves, A.; Welker, C.; Ferreira, F.; Carvalho, M.; Silva, A.; Reis, P.; Dórea, M.; Silva, C. \& Mota, A. 2014. Poaceae. In: Lista de Espécies da Flora do Brasil. Jardim Botânico do Rio de Janeiro. Disponível em <http://floradobrasil.jbrj. gov.br/jabot/floradobrasil/FB193>. Acesso em 4 julho 2014.

GPWG - The Grass Phylogeny Working Group. 2001. Phylogeny and subfamilial classification of the grasses (Poaceae). Annals of the Missouri Botanical Garden 88: 373-457.

Jacomine, P.; Cavalcanti, A.; Pessoa, S.; Burgos, N.; Melo Filho, H.; Lopes, O. \& Medeiros, L. 1986. Levantamento exploratório-reconhecimento de solos do Estado do Piauí. Embrapa/SNLCS/ Sudene, Rio de Janeiro. 782p.

Longhi-Wagner, H. 1987. Flora Ilustrada do Rio Grande do Sul. Fasc. 17. Gramineae - tribo Poeae. Boletim do Instituto de Biociências 41: 1-191.

Longhi-Wagner, H. 2012. Poaceae: an overview with reference to Brazil. Rodriguesia 63: 89-100.

Lorenzi, H. 2006. Manual de identificação e controle de plantas daninhas: plantio direto e convencional. Editora Plantarum, Nova Odessa. 339p.
Maciel, J.; Oliveira, R. \& Alves, M. 2009. Paspalum L. (Poaceae: Panicoideae: Paniceae no estado de Pernambuco, Brasil. Acta Botânica Brasílica 23: 1145-1161.

Maciel, J.; Oliveira, R. \& Alves, M. 2010. Aspectos da distribuição e conservação de Paspalum L. (Poaceae) em Pernambuco. Hoehnea 37: 801-812.

Maciel, J.; Oliveira, R.. \& Alves, M. 2014. Flora da Usina São José, Igarassu, Pernambuco: Poaceae. Rodriguesia 65: 355-367.

Nascimento, M. \& Renvoize, S.A. 2001. Gramíneas forrageiras naturais e cultivadas na região meionorte. Embrapa Meio-Norte, Teresina. 196p.

Oliveira, R. \& Valls, J. 2002. Taxonomia de Paspalum L., Grupo Linearia (Graminea-Paniceae) do Brasil. Revista Brasileira de Botânica 25: 371-389.

Oliveira, R. \& Valls, J. 2008. Novos sinônimos e ocorrências em Paspalum L. (Poaceae). Hoehnea 35: 289-295.

Oliveira, R.; Santana, S.; Silva, A.; Maciel, J. \& Valls, J. 2013. Paspalum (Poaceae) no Rio Grande do Norte, Brasil. Rodriguesia 64: 847-862.

Pimenta, K.; Dórea, M. \& Oliveira, R. 2012. Panicoideae (Poaceae) em remanescentes florestais do sul da Bahia: aspectos taxonômicos e ecológicos. Rodriguesia 63: 933-955.

Pfaltzgraff, P. 2010. Geodiversidade do estado do Piaui. Programa Geologia do Brasil levantamento da Geodiversidade. In: Pfaltzgraff, P.; Torres, F. \& Brandão, R. Serviço Geológico do Brasil. CPRM, Recife. 260p.

Renvoize, S. 1984. The grasses of Bahia. Royal Botanic Gardens, Surrey. 301p.

Silva, R. 2000. Gramíneas (Poaceae) da Área de Relevante Interesse Ecológico (ARIE) Santuário de Vida Silvestre do Riacho Fundo, DF-Brasil. Dissertação de Mestrado. Universidade de Brasilia, Brasília. 135p.

Skerman, P. \& Riveros, F. 1992. Gramíneas tropicales. FAO, Roma. 576p.

Viana, P. \& Filgueiras, T. 2008. Inventário e distribuição geográfica das gramíneas (Poaceae) na cadeia do Espinhaço, Brasil. Megadiversidade 4: 72-88 